\title{
The effect of aging and duration of disability on long term health outcomes following spinal cord injury
}

\author{
W Pentland ${ }^{1}$, MA McColl ${ }^{2}$ and C Rosenthal \\ ${ }^{1}$ School of Rehabilitation Therapy, Queen's University, Kingston, Ontario, Canada K7L 3N6; ${ }^{2}$ Office of \\ Gerontological Studies, McMaster University, Hamilton, Ontario, Canada
}

The purpose of the study was to discover the independent and combined effects of age and duration of injury on selected long term health outcomes of 83 spinal cord injured (SCI) men (age range 21-79 years; duration of spinal cord injury 3-52 years). Specifically, the study examined a multivariate model which specified that age, duration, the interaction of age and duration, and level of lesion were related to the following health outcomes: pain, fatigue, functional independence, mobility, illness and symptomatology, perceived overall health, social support, life satisfaction, and economic stability. Age had significant main effects on three outcomes. With increasing age, the sample experienced more fatigue, decreased activity (due to pain), and more overall satisfaction with their lives. Duration of SCI showed significant main effects on two outcomes. As subjects lived longer with their $\mathrm{SCI}$, they felt less financially secure and experienced more symptoms and illnesses. Significant interaction effects of age and duration of SCI were found for two outcomes. Older age combined with longer duration of SCI amplified subjects' perceptions of financial insecurity, and threats to health. The findings send a clear message to service-providers and policy makers about the added vulnerability of older disabled individuals, about the need for extra vigilance in health care issues, and about the necessity of a social-economic safety net for already disadvantaged individuals.

Keywords: spinal cord injury; quality of life; aging; long term outcome

\section{Introduction}

The life expectancy of persons with spinal cord injury (SCI) has increased dramatically in the past 20 years as a result of scientific advances in medical care and rehabilitation. ${ }^{1,2}$ Only recently, however, has information become available about the effects of longevity on disabled individuals. With the passage of time, these people must cope with the effects of two simultaneous processes: aging and increasing duration of disability. Research to date has only begun to recognize that aging and duration of disability are two discrete factors, with potentially independent effects on outcomes. The aim of this research was to begin to disentangle the effects of long term disability from the effects of aging.

Persons with long term SCI have reported that, as a result of surviving longer than any previous cohort of severely disabled people, they are having to break new ground. ${ }^{3}$ There has been a lack of information and research available to plan services that are designed to meet their needs. In order to plan timely and relevant programs for this group, the impact of both increasing age and increasing duration of spinal cord injury need to be understood.

Recently there have been a number of published studies of the effects of long term disability, including spinal cord injury. ${ }^{4-12}$ Changes have been reported in mobility, independence, social support, life satisfac- tion, quality of life, and economic stability, ${ }^{13-18}$ However, very few have specifically examined the effects of increased duration of disability, or the interaction between duration of disability and the aging process. Duration of SCI and age are often significantly correlated in spinal cord injured samples. ${ }^{11,13,19-21}$ In those studies that have considered both age and duration of disability, it is not clear whether and how one variable was controlled while examining the other. ${ }^{9,13,16,18}$ As a result, while some information is available as to the effects of time on persons with spinal cord injury, whether to expect changes after 15 or 20 years of SCI, or not until later life, is not year clear.

While it is important to understand the effects of aging on persons with long term disability, it is essential in the sample population also to recognize the effects of duration of disability. Since the mean age of onset of SCI is 29 years, ${ }^{22}$ someone $15-20$ years post injury might only be in his/her forties. Focusing solely on the effects of aging will risk missing those effects of long term disability that may occur at a relatively young age.

Following interviews of 34 persons with an average duration of SCI of 22 years, and a relatively young mean age (45 years), Corbett (1987) noted that this group had already begun to report increased levels of fatigue, pain, and various physical problems. ${ }^{23}$ The subjects feared that their independence would be 
jeopardized by the effects of both their own aging and the aging of their caregivers. The young mean age of this group highlights the need for more information regarding the impact of duration of disability on long term outcomes in persons with spinal cord injury.

Based on clinical observation, it has been suggested that persons with SCI experience premature physiological aging, which in turn decreases their physical and emotional reserves to withstand disease, fatigue, or handicap. ${ }^{24}$ Findings from studies of persons with longer term paraplegia suggest that the prevalence of upper limb pain and pathology is associated more with increased duration of injury than with chronological age. ${ }^{4,7,8,19,20}$ However, in only one of these studies, ${ }^{19,20}$ the research design and analysis permit the confounding effects of age and duration of SCI to be separated, with the findings suggesting that duration of SCI influences the development of shoulder pain more than older age.

The study of human aging is a vast and complex field with ongoing efforts to develop and test comprehensive theories of aging that incorporate biological, social, psychological, and cultural factors. ${ }^{25,26}$

Aging is a multifaceted phenomenon and the process and patterns vary among individuals and groups depending on rate of biological change, changes in physical or mental health, environmental changes, and previous and current economic status. ${ }^{27,28}$ When interpreting studies of aging, gerontologists attempt to differentiate between three influences. These are maturational or aging changes; changes caused by period or historical effects; and differences between ages that are characteristics that persist throughout each group's lifespan. These latter cohort or generational effects are in part a function of the age-group's intersection with history. ${ }^{29}$ Based on her examination of spinal cord injury, and later life, Trieschmann outlined a model to explain the impact of aging on this population. She proposed that the functional behaviour of persons with spinal cord injury results from their achievement of a tenuous equilibrium between their organic and psychosocial abilities and their environment; and that the biological changes associated with aging disturb this balance, necessitating adjustment and compensation in the psychosocial and environmental realms. ${ }^{30}$

There have been extensive investigations into the problems encountered by the able bodied population as they age. Common problems include: declining health, activity limitations and dependency, declining income, and widowhood. Health and income have been identified as the two factors most highly correlated with well being and the ability to retain independence in later life. ${ }^{31}$ Current research shows that people with spinal cord injuries report similar issues associated with aging, specifically: loss of independence, financial concerns, and social isolation. ${ }^{11,21}$ However, Krause and Crewe (1990) surveyed a young sample with long duration spinal cord injury ( $>15$ years) and found similar concerns: lack of income, pain, lack of access, health problems, boredom, and dependency. ${ }^{10}$ Thus, the effects of duration of SCI versus chronological age are not clear.

In order to plan programs, services, and interventions that meet the needs of persons with SCI, we need to understand the effects of time on this population. This includes being able to identify and anticipate the effects of aging on persons with SCI, as well as understanding the changes that are associated with duration of disability or the interaction of the two. The specific objectives of this study were to determine, in persons with a long term spinal cord injury, which of a list of issues commonly associated with aging are functions of age, which are functions of long term disability, and to describe the interaction of the two.

\section{Methods}

The purpose of the study was to discover the independent and combined effects of age and duration of SCI on selected long term health outcomes in spinal cord injured men. Specifically, the study examined a multivariate model which specified that age, duration, the interaction of age and duration, and level of lesion were related to the following health outcomes: pain, fatigue, functional independence, mobility, activity level, illness and symptomatology, perceived overall health, social support, life satisfaction, and economic stability.

Multiple regression analyses were undertaken to test the models described above. In all, thirteen equations were evaluated: one for each of the outcomes of interest. In each case, four variables were initially entered in each equation: age, duration of spinal cord injury, a multiplicative interaction term of age and duration, and level of lesion. A backwards stepwise approach was taken, with the criterion $(P<0.10)$ for variables to remain in the equation, and $(P<0.05)$ for variables to be considered significant.

Subjects

A toal of 83 men with a traumatic spinal cord injury were recruited from the records of the Lyndhurst Spinal Cord Centre (LSCC), the Bawden Rehabilitation Unit of Kingston General Hospital, and the membership of the Canadian Paraplegic Association Ontario (CPAO). Women were excluded from the sample in recognitiion of the known influence of gender on the aging process and on coping with a disability. Work is currently underway to reproduce the study with women.

Since chronological age and duration of disability have been shown to be correlated in spinal cord injured samples, ${ }^{11,13,19-21}$ the sample was carefully selected to allow analysis of the effects of these two independent variables.

Sampling was purposive and subjects were recruited into the four categories; young age short duration; young age long duration; old age short duration; old age long duration (Table 1). Although age and duration of SCI were used as continuous variables in the data analysis, sampling age and duration were considered 
Table 1 Definition of the four subject categories

\begin{tabular}{lcc}
\hline Duration of $S C I$ & \multicolumn{2}{c}{ Age } \\
\hline & $<40$ years & $>50$ years \\
$<5$ years & 20 & 20 \\
$>15$ years & 20 & 23 \\
\hline
\end{tabular}

two categories (aged less than 40 years and aged more than 50 years; injured less than 5 years and injured longer than 15 years), in order to obtain a maximum contrast in these variables within the sample. The age of 50 years was selected as the cut-off for the older group for two principal reasons. Firstly, the literature suggests that persons with spinal cord injury may experience 'premature aging'. $5,18,23,24$ Furthermore, the more subtle age-related changes known to be experienced by able bodied persons in their fifties may have very profound functional implications for persons with disabilities. ${ }^{31,32}$ Descriptive statistics for the sample are provided in Table 2.

\section{Procedures}

Ethics review and informed subject consents were completed. Potential subjects were recruited via a mailed information letter followed by a telephone call to explain the study. Of 88 persons contacted five refused, leaving the final sample of 83 . Participants were then interviewed in their own home (as distance permitted) or by telephone, by a trained interviewer. Interviews lasted approximately $1 \mathrm{~h}$. Information was collected on the following variables: independent variables: age, duration of SCI; dependent variables: overall perceived health, pain, symptoms, fatigue, functional independence, satisfaction with mobility, social support, financial security, activity level, and life satisfaction; and confounding variable: lesion level.

\section{Instruments}

The instruments are described below. Prior to analysis, the psychometric performance of the instruments

Table 2 Descriptive statistics for the sample $(n=83)$

\begin{tabular}{lc}
\hline Age range X (SD) & $21-79$ years \\
& $50.2(15.4)$ years \\
Duration of SCI range X (SD) & $3-52$ years \\
& $18.3(16.5)$ years \\
Correlation of age and duration & $r=0.047(P<0.000)$ \\
of SCI & \\
Lesion levels & 38 \\
$\quad$ Cervical & 34 \\
Thoracic & 11 \\
Lumbar & \\
Employment & 64 \\
Unemployed/retired/student & 19 \\
Employed full/part-time & \\
Marital status & 39 \\
$\quad$ Note living with partner & 44 \\
Living with partner & \\
\hline
\end{tabular}

with this sample was checked using factor analysis to confirm unidimensionality, and Cronbach's alpha to confirm internal consistency reliability.

Generally, unidimensionality was shown to be very high, with a range of first factor loadings of $53-75 \%$. For two instruments, the factor loadings were lower, and these are discussed below (life satisfaction and pain). Internal consistency reliability for all scales was also good (range $r=0.057-0.96$ ).

Perceived health was assessed using two single Likert indicators that addressed current state of health and future concerns. The items have been used previously with a variety of aging and disabled populations. ${ }^{11,21,34,36}$

Pain was measured usng the Multidimensional Pain Inventory (MPI) ${ }^{37,38}$ The inventory consists of three sections designed to measure subjects' perceptions of pain experience, its impact on their daily functioning, and pain effects on the spouse. The instrument consists of 61 Likert-scaled response items, and generates a percentage score. This multidimensional pain assessment has reportedly demonstrated good reliability and validity. ${ }^{37}$

Based on statistical evaluation of the inventory's performance in this study, the subsections were modified prior to analysis. In Section I: Pain Perception, seven of the 28 items were eliminated due to low or negative item total correlations. For the same reason, one of the 14 items in Section II: Response of Significant Others, and four of the 19 items in Section III: Activity level were eliminated. Subsequent to the modifications, for all three subscales, the first factor still explained a fairly small proportion of the variance (Section I: 47\% ; Section II: 35\% ; Section III: 39\%), although the internal consistency reliability coefficients were high (Section I: $r=0.93$; Section II: $r=0.91$; Section III: $r=0.89$ ). The instrument was originally designed for persons with rheumatoid arthritis, which may explain, in part, the low item total correlations.

Subjects were asked to identify their current conditions/symptoms from a prepared list of 18 items. Due to the disparate nature of the checklist items, unidimensionality was not expected or found. Internal consistency reliability was good $(r=0.57)$.

Fatigue was measured using the Fatigue Severity Scale (FSS).$^{39}$ The instrument was designed to evaluate the severity of fatigue and its impact on daily functioning. A composite numerical score is derived from nine Likert model statements. Internal consistency, validity, sensitivity, and test-retest reliability have been established.$^{39}$ Normative data are available for healthy able bodied adults.

Functional independence was measured using the Functional Independence Measure (FIM) ${ }^{40}$ The FIM is a brief, standardized measure of activities of daily living, used widely in rehabilitation. It results in a percentage score, and normative data are available for a number of populations.

Subjects' satisfaction with mobility was measured using three items related to mobility from the Reintegration to Normal Living Index (RNL) ${ }^{41}$ The RNL was 
developed to measure the extent of reorganization of physical, social, and psychological characteristics of an individual so that they can resume well-adjusted living after illness or trauma.

Social support was measured using an adaptation of Interpersonal Support Evaluation List (ISEL). ${ }^{42}$ The ISEL asks individuals about the perceived availability of someone to provide specific support functions in each of the areas of instrumental support, emotional support, and informational support. Psychometric evaluation of the original 40 items ISEL estimates internal consistency at $0.77-0.90$ and two day testretest reliabilty at 0.87 . Subsequent measurement development with the spinal cord injured population by McColl and Skinner (1993), has resulted in a 33-item version based on empirical evaluations with a provincewide sample of 223 spinal cord injured adults. ${ }^{43}$

Financial security was assessed using the Financial Stress Scale (FSS) ${ }^{44}$ which measures the degree of current financial strain in various areas of an individual's life. In addition, amount and source of income questions were adapted from the Health and Activity Limitation Survey (1988) on the demographic data collection form. . $^{34}$

A 12 -item measure of life satisfaction was used..$^{45,46}$ The items tap satisfaction with health, finances, family relations, employment, friendships, housing, living situation, recreation, religion, self esteem, transportation, and life in general. The measure is widely used, and has good reliability and validity. With our sample, the first factor explained a relatively small proportion of the variance $(38 \%)$, but the internal consistency reliability was high $(r=0.78)$. The unexplained variance may result from the heterogeneous nature of the items contributing to life satisfaction (health, finances, family relations, housing, religion, transportation, etc). Krause (1992) also found that life satisfaction post SCI is not a unidimensional construct. ${ }^{9}$ However, the high internal consistency reassures us of the inherent relatedness of the 12 aspects of life satisfaction.

\section{Results}

For six of the outcomes of interest (mobility, pain experience, pain effect on spouse and all three types of social support), the model containing level of lesion, and mean and interaction effects of age and duration, was found not to explain a significant amount of variance (Table 3 ).

For one of the outcomes, functional independence, only the confounding variable, level of lesion was found to be significantly related to outcome. As expected, the higher the lesion, the lower the individual's functional ability.

For the remaining six outcomes (mobility, pain experience, pain effect on spouse and all three types of social support), age and duration of disability were found to have significant main and/or interaction effects.

Age was found to have a significant positive main effect on fatigue and life satisfaction, and a negative main effect on activity level (Table 4). Thus with increasing age, our sample experienced more fatigue, a reduced activity level, and more overall satisfaction with their lives.

Duration of spinal cord injury was negatively related to economic stability, and positively related to the number of symptoms experienced. As study participants lived longer with their injury, they experienced a diminished sense of economic security, and more symptoms and illnesses.

Interaction effects of age and duration were detected in relation to two of the outcomes of interest. A positive interaction was evident in relation to economic stability, in addition to the main effect of duration just mentioned. Thus while subjects experienced less economic stability as they lived longer with their injury,

Table 3 Outcomes not affected by age and duration of spinal cord injury

\begin{tabular}{lccc}
\hline Outcome & $F$ & d.f. & P value \\
\hline Mobility & 0.62 & 78,4 & 0.647 \\
Pain (perception) & 0.10 & 78,4 & 0.980 \\
Pain (spousal response) & 0.98 & 39,4 & 0.430 \\
Social support (emotional) & 0.81 & 77,4 & 0.520 \\
Social support (informational) & 0.35 & 76,4 & 0.843 \\
Social support (instrumental) & 0.59 & 78,4 & 0.671
\end{tabular}

Table 4 Main and interaction effects of age and duration on outcomes

\begin{tabular}{|c|c|c|c|c|}
\hline Outcomes & Model satistics & Main effects: age & Main effects: duration & Interaction \\
\hline Economic stability & $\begin{aligned} F_{(79,2)} & =7.19 \\
P & =0.001\end{aligned}$ & & $\begin{aligned} t & =-2.95 \\
P & =0.004\end{aligned}$ & $\begin{aligned} t & =3.38 \\
P & =0.001\end{aligned}$ \\
\hline Fatigue & $\begin{aligned} F_{(80,1)} & =5.12 \\
P & =0.026\end{aligned}$ & $\begin{aligned} t & =2.26 \\
P & =0.026\end{aligned}$ & & \\
\hline Perceived health & $\begin{aligned} F_{(81,1)} & =4.09 \\
P & =0.047\end{aligned}$ & & & $\begin{aligned} t & =2.02 \\
P & =0.047\end{aligned}$ \\
\hline Life satisfaction & $\begin{aligned} F_{(77,1)} & =10.15 \\
P & =0.002\end{aligned}$ & $\begin{aligned} t & =3.18 \\
P & =0.002\end{aligned}$ & & \\
\hline Pain (activity level) & $\begin{aligned} F_{(72,2)} & =5.92 \\
P & =0.004\end{aligned}$ & $\begin{aligned} t & =2.71 \\
P & =0.009\end{aligned}$ & & \\
\hline Symptoms & $\begin{aligned} F_{(79,1)} & =8.24 \\
P & =0.005\end{aligned}$ & & $\begin{array}{l}t=2.87 \\
P=0.005\end{array}$ & \\
\hline
\end{tabular}


this effect was amplified or aggravated when old age was combined with increased duration.

A positive interaction effect of age and duration was also found in relation to perceived health, in the absence of main effects for either age or duration. This suggests that while neither age nor duration alone significantly affected perceived health, the two together had a significant effect on the perception of health.

\section{Discussion}

To summarize, the study shows that the age of a man with a SCI has a direct effect on his life satisfaction, activity level, and fatigue. Further it shows that the duration of injury has a direct effect on health and economic stability; and that the effect of duration is exaggerated in the presence of old age for older spinal cord injured male adults.

As regards the relationships between chronological age and outcomes, it appears from this study that regardless of duration of injury, as men with SCI grow older, they experience increased fatigue, their activity level decreases, and their life satisfaction improves. As this is a cross-sectional study, the results need to be interpreted carefully since there is no longitudinal dimension and certain exposure variables, such as environmental effects, may have changed over time or varied among different age cohorts.

The findings regarding fatigue seem consistent with previous studies. In her review of literature on aging and spinal cord injury, Crewe (1990) concluded that fatigue was the most common complaint. ${ }^{47}$ Gerhart et al (1993) also found fatigue to be a major concern for their aging sample. ${ }^{14}$ Assuming that fatigue is related to losses of muscle strength, Pentland and Twomey (1993) found that age predicted strength declines in some upper limb musculature, but better predictors tended to be factors such as duration of spinal cord injury and lesion level..$^{19,20}$ Fatigue itself is a complex multifactorial phenomenon and may result from a variety of causes, such as poor sleep, depression, or anxiety, as well as decreased muscle strength, endurance, or pathology. Pathology likely was a factor in the fatigue indicated by some subjects since $19 \%$ reported having had a significant illness, injury, or surgery in the past year. ${ }^{48,49}$ This study examined self-perceived fatigue and did not attempt to determine cause. However, it is important to note that intervention against fatigue may be possible. While muscle strength does decline with age in the general population, Vandervoort, Hayes and Belanger (1986) have found that it is trainable throughout the lifespan, and that conditioning can offset, at least in part, age-related declines. ${ }^{31}$

The study also found decreases in activity level related to increasing age. This finding may be due to strength losses, reduced endurance, or general fatigue, but numerous other factors have also been found to influence activity level in older persons with disabilities, including pain and stiffness, medical problems ${ }^{14}$ and income.${ }^{50}$ Of note in this study is that although age is related to increased fatigue and reduced activity levels, functional independence did not appear to decline with age. It may be that fatigue does not (or subjects do not let it) interfere with the type of self care activities measured by the FIM, but that with age, fatigue does constrain the normally more rewarding activities related to getting out and interacting in the community.

With regard to the relationship between age and life satisfaction, there appears to be a lack of consensus in the literature as to how life satisfaction changes with age in persons with spinal cord injury. ${ }^{13,15,16,18}$ Further, in the majority of studies, it is not clear how the potential confounding effects of duration of injury were managed in the analyses. Life satisfaction in the SCI population has been shown to decrease with age; ${ }^{18}$ increase or remain stable ${ }^{15}$ and not be related to age at all. ${ }^{13,16}$ In the present study, life satisfaction was explained by age, independent of duration of injury. The reason for this may be in part either a cohort or historical effect secondary to different social and environmental conditions over time. ${ }^{15}$ It may also be due in part to the fact that, unlike previous studies, our analysis controlled for the effects of duration of injury. Nevertheless, it must be acknowledged that the examination of life satisfaction in the SCI population is complex, as it appears to be a multidimensional construct. ${ }^{5,9}$ It follows then, that the varying content of the measurement instruments used in different studies will influence the outcome. Furthermore, this is a cross-sectional study, and the difference in life satisfaction between age groups, exclusive of duration of injury, may simply be a reflection of differing expectations and values between the younger and older age cohorts. Longitudinal studies would help to unmask this effect.

As regards the relationships between duration of spinal cord injury and outcomes, the findings were that in men, independent of age, duration of spinal cord injury predicted an increase in medical symptoms, and a decrease in perceived financial security.

In contrast to our findings, a longitudinal study of persons with SCI found that satisfaction with finances improved over time. ${ }^{15}$ Explanations for the difference in findings between the two studies include the use of longitudinal versus cross-sectional methods, and demographic (cohort) differences between the two samples. The sample in this study differed from Krause's (1992) in that it was on average older and injured longer. ${ }^{15}$ Further, $23 \%$ of our sample were employed versus $50 \%$ employed in Krause's (1992) study. ${ }^{15}$ Finally the studies were conducted in different countries (Canada and USA), where health care, financial, and social support programs for persons with disabilities are known to differ.

The negative effect of duration of SCI on perceived financial security was even further exacerbated by increased chronological age. In this sample, financial security may have been perceived to be threatened by an expected increase in medical symptoms and increased age and duration. The financial impact of these increased symptoms would be experienced in their 
decreased ability to work, and the added need for assistive devices and paid assistance.

The most frequently reported increase in medical symptoms experienced by those subjects with longer durations of SCI were bladder infections, stomach problems, pressure sores, respiratory problems, fatigue, and bowel problems. It is not clear why perceived health did not also decline with duration of SCI, as medical symptoms increased. Perhaps to some extent the subjects expected increased symptoms over time, and thus in ratings of perceived health, there was no discrepancy between their actual and expected health with duration of SCI. Whiteneck et al (1992) also reported an increase in symptoms over time in persons with SCI, but it is not clear how the effects of age and duration were separated out. ${ }^{18}$ They found age to be more associated with systemic problems (cardiac, internal, and nervous systems) and duration of SCI to be more associated with musculoskeletal problems. In the general population, an age-related increase in medical symptoms has also been documented. ${ }^{32}$ The association of increased symptoms with duration of injury in the SCI population suggests that some of these symptoms may occur earlier in adulthood in those with long term spinal cord injuries.

With regard to interactive effects, age and duration interacted to compound the negative effects of age on perceived financial security, as discussed above. Perceived health was also negatively affected by the combined effects of age and duration of SCI. Consistent with our findings, Fuhrer et al (1992) found no main effect of either age or duration of SCI on perceived health, but they do not appear to have examined interaction effects. ${ }^{13}$

A number of the outcome variables examined were found not to be explained by age, duration of SCI, or the interaction of the two. These variables were: functional independence, satisfaction with mobility, two subscales of pain (perception, spouse response), and three dimensions of social support (instrumental, emotional, informational). There is only a small body of literature examining the impact of time (age and/or duration of SCI) on these variables in the spinal cord injured population. Whiteneck et al (1992) found that mobility declines with age, but not with duration of SCI. ${ }^{18}$ In our study, satisfaction with mobility (home, community, out of town), rather than mobility per se, was measured. It is not clear specifically how Whiteneck et al (1992) measured mobility, but it appears that they combined items related to satisfaction and frequency of outings. ${ }^{18}$ Based on our findings, it appears that although number and frequency of outings may change over time, satisfaction with mobility does not. As outlined in the discussion of life satisfaction, there may be a cohort or historical influence here, related to the older subjects' expectations for their mobility level in later life.

The experience of pain, and significant other's response to it was not predicted by age or duration of SCI in our study. In a study of men with paraplegia, shoulder pain was shown to be associated with duration of injury, exclusive of age.$^{19,20}$ Differences in findings may be explained by the data collection instruments and the inclusion of persons with tetraplegia in the sample of this study.

The failure of age or duration of SCI to predict the perceived availability of various types of social support is a positive finding, and is congruent with research on the general population which suggests social network size is similar among middle-aged and older adults ${ }^{51}$ and that older people are satisfied with the adequacy of their social networks. ${ }^{52}$ Fuhrer et al (1992) also examined social support in a long term SCI sample and found it was not related to either age or duration of SCI. ${ }^{13}$

While increased age was related to decreased activity levels in this sample, functional independence, as measured by the FIM, was not. The tasks rated in the FIM are primarily self care tasks. It may be that independent performance of these tasks in persons with SCI does not decline until well into later life. Fuhrer $e t$ al (1992) also found no relationship between function as measured by the FIM and age, and duration of SCI. ${ }^{13}$ In contrast, using other measures, Gerhart et al (1993) and Whiteneck et al (1992) found that function appeared to decline with age, but it is not clear how either controlled for duration of SCI..$^{14,18}$

\section{Conclusions}

In conclusion, the study clarifies the relationships in men of age and duration of SCI to a variety of important outcomes. In males, age appears to affect outcomes that are not obviously related to the presence of SCI: fatigue, life satisfaction, and activity level. Duration, on the other hand, especially when combined with old age, affects two outcomes that are essential to satisfactory survival of disabled individuals through older age: health and financial security.

\section{References}

1 Eisenberg MG, Falconer J (eds). Treatment of the Spinal Cord Injured. Charles C Thomas: Springfield, 1978.

2 DeVivo MJ, Fine PR, Stover SL. Seven year survival following spinal cord injury. In: American Spinal Injury Association's Tenth Annual Scientific Meeting Abstracts Digest, 1984, pp 71-76.

3 Maddox S. Spinal Network. Sam Maddox: Boulder, Colorado, 1987, p 41.

4 Aljure $\mathrm{J}$ et al. Carpal tunnel syndrome in paraplegic patients. Paraplegia 1987; 23: 182-186.

5 Cushman LA, Hassett J. Spinal cord injury: 10 and 15 years after. Paraplegia 1992; 30: 690-696.

6 Davidoff G, Werner R, Waring W. Compressive mononeuropathies of the upper extremity in chronic paraplegia. Paraplegia 1991; 29: 17-24.

7 Gellman $\mathrm{H}$ et al. Carpal tunnel syndrome in paraplegic patients. J Bone Joint Surg Am, 1988; 70: 517-519.

8 Gellman H, Sie I, Water R. Late complications of the weight bearing upper extremity in the paraplegic patient. Clin Orthop 1988; 233: 132-135.

9 Kraus JS. Longitudinal changes in adjustment after spinal cord injury: A 15-year study. Arch Phys Med Rehabil 1992; 73: 564-568.

10 Krause JS, Crewe NM. Long term prediction of self-reported 
problems following spinal cord injury. Paraplegia 1990; 28: 186-202.

11 McColl MA, Rosenthal C. A model of resource needs of aging spinal cord injured men. Paraplegia 1994; 32: 261-270.

12 Pentland W, Twomey LT. The weight-bearing upper extremity in women with longterm paraplegia. Paraplegia 1991; 29: 521-530.

13 Fuhrer MJ et al. Relationship of life satisfaction to impairment, disability, and handicap among persons with spinal cord injury living in the community. Arch Phys Med Rehabil 1992; 73: 552-557.

14 Gerhart KA et al. Long-term spinal cord injury: Functional changes over time. Arch Phys Med Rehabil, 1993; 74: 1030-1034.

15 Kraus JS. Life satisfaction after spinal cord injury: A descriptive study. Rehabil Psychol 1992; 37: 61-70.

16 Kraus JS, Dawis RV. Prediction of life satisfaction after spinal cord injury: A four year longitudinal approach. Rehabil Psychol 1992; 37: 49-59.

17 Siosteen $\mathrm{M}$ et al. The quality of life of three functional spinal cord injury subgroups in a Swedish community. Paraplegia 1990; 28: 476-488.

18 Whiteneck G et al. Mortality, morbidity, and psychosocial outcomes of persons spinal cord injured more than 20 years ago. Paraplegia 1992; 30: 617-630.

19 Pentland W, Twomey LT. Upper limb function in persons with longterm paraplegia and implications for independence: Part II. Paraplegia, 1994; 32: 219-224.

20 Pentland W, Twomey LT. Upper limb function in persons with longterm paraplegia and implications for independence: Part I. Paraplegia 1994; 32: 211-218.

21 McColl MA, Rosenthal C. Resource needs expressed by aging spinal cord injured men. Arch Phys Med Rehabil (submitted).

22 Stover S, Fine R (eds). Spinal Cord Injury: The Facts and Figures. University of Alabama: Birmingham, Alabama, 1986, p 69.

23 Corbett B. Options revisited. In: Maddox S (ed). Spinal Network. Sam Maddox: Boulder, Colorado, pp 12-19.

24 Ohry A, Shemesh Y, Rozin R. Are chronic spinal cord injured patients (SCIP) prone to premature aging? Med Hypotheses, 1983; 11: 467-469.

25 Streib GF, Binstock RH. Aging and the social sciences changes in the field. In: Binstock R and George LK (eds). Handbook of Aging and the Social Sciences, 3rd edn. Harcourt, Bruce, Joranovich: San Diego, 1990, p 1.

26 Novak M. Aging and Society: A Canadian Perspective, 2nd edn. Nelson Canada: Scarborough, 1993, p 33.

27 McPherson BD. Aging as a Social Process. Butterworth \& Co: Toronto, 1983, p 3.

28 Myers G. Demography of aging. In: Binstock R, George LK (eds). Handbook of Aging and the Social Sciences, 3rd edn. Harcourt, Bruce, Joranovich: San Diego, 1983, p 19.

29 Bengston VL, Cutler NE. Generations and intergenerational relations: Perspectives on age groups and social change. In: Binstock R and Shanas E (eds). Handbook of Aging and the Social Sciences. Van Nostrand Reinhold: New York, 1983, p 196.

30 Trieschmann R. Aging with a Disability. Demos: New York, 1987, pp 44-59.

31 Vandervoort AA, Hayes KC, Belanger AY. Strength and endurance of skeletal muscle on the elderly. Physiother Can 1986; 38: 167-173.

32 Williams TF (ed). Rehabilitation in the Aging. Raven: New York, 1984, pp 1-35.

33 Verbrugge LM. Gender, aging, and health. In: Aging and Health: Perspectives on Gender, Race, Ethnicity, and Class. SAGE Publications Inc: Newburg Park, 1989, pp 105-131.

34 Satistics Canada. The Health and Activity Limitation Survey: User's Guide. Ministry of Supply and Services: Ottawa, 1988, p 29.

35 Marshall V, Chappell N. A study of the needs of elderly people in Bermuda. Interview Schedule. Centre for Studies of Aging, University of Toronto, Toronto.

36 McColl MA, Skinner HA. Assessing inter- and intra-personal resources for community living. Final Report No. 6606-4127-61. Canadian National Health Research Development Program, Ottawa, Ontario.

37 Kerns RD, Turk DC, Rudy TE. The West Haven Yale Multidimensional Pain Inventory (WHYMPI). Pain 1985; 23: 345-356.

38 Turk DC, Rudy TE. Toward a comprehensive assessment of chronic pain patients: A multiaxial approach. Behav Res Ther 1987; 25: 237-249.

39 Krupp EB, LaRocca NG, Muir-Nash J, Steinberg AD. The fatigue severity scale. Arch Neurol 1989; 46: 1121-1123.

40 Keith RA, Granger CV, Hamilton BB, Sherwin FS. The Functional Independence Measure: A new tool for rehabilitation. In: Eisenberg MG, Grzesiak RG (eds). Advances in Clinical Rehabilitation. Springer: New York, 1987, pp 6-8.

41 Wood-Dauphinee S, Williams I. Reintegration to normal living as a proxy to quality of life. J Chron Dis 1987; 40: 491-499.

42 Cohen S, Mermelstein R, Kamarck T, Hoberman H. Measuring the functional components of social support. In: Gardson IG, Sarson BR (eds). Social Support: Theory, Research, Application. Martinus Nijhoff Publisher: Boston, 1985, pp 73-74.

43 McColl MA, Skinner H. Assessing inter and intra-personal resources for community living. Int Disabil Stud (in press).

44 Feather NT. Financial Stress Scale. In: The Psychological Impact of Unemployment. Springer-Verlag: New York, 1989: 105.

45 Michalos A. Satisfaction and happiness. Soc Indicators Res 1980; 8: 385-422.

46 Michalos A. Multiple discrepancies theory. Soc Indicators Res 1985; 16: 347-413.

47 Crewe NM. Aging and severe physical disability: Patterns of change and implications for service. Educ Gerontol 1990; 16: 525-534.

48 Berly MH, Strauser WW, Hall KM. Fatigue in post polio syndrome. Arch Phys Med Rehabil 1991; 72: 115-118.

49 Packer TL, Martin I, Krefting L, Brouwer B. Post polio sequelae: Activity and post polio fatigue. Orthopedics 14: 1223-1226.

50 Osberg JS, McGinnis GE, DeJong G, Seward ML. Life satisfaction and quality of life among disabled elderly adults. $J$ Gerontol 1987; 42: 228-230.

51 Antonucci T. Social supports and social relationships. In: Binstock R, George LK (eds) Handbook of Aging and the Social Sciences, 3rd edn. Academic: California, 1990, pp 205-220.

52 Chappell N. Social Support and Aging. Butterworths: Toronto and Vancouver, 1992, p 107. 